\title{
Time-Lapse Seismic Monitoring of Onshore Reservoirs in Niger Delta, Field ' $K$ ' as a Case Study
}

\author{
Ogbamikhumi, A. ${ }^{1 *}$, Tralagba, T. ${ }^{2}$ and Osagiede E.E. ${ }^{1}$ \\ ${ }^{1}$ Department of Geology, University of Benin, Benin City, Nigeria \\ ${ }^{2}$ University of Nigeria, Nsukka, Nigeria \\ Corresponding Author: *alexander.ogbamikhumi@uniben.edu
}

\begin{abstract}
Field ' $K$ ' is a mature field in the coastal swamp onshore Niger delta, which has been producing since 1960. As a huge producing field with some potential for further sustainable production, field monitoring is therefore important in the identification of areas of unproduced hydrocarbon. This can be achieved by comparing production data with the corresponding changes in acoustic impedance observed in the maps generated from base survey (initial 3D seismic) and monitor seismic survey (4D seismic) across the field. This will enable the $4 D$ seismic data set to be used for mapping reservoir details such as advancing water front and un-swept zones. The availability of good quality onshore time-lapse seismic data for Field ' $K$ ' acquired in 1987 and 2002 provided the opportunity to evaluate the effect of changes in reservoir fluid saturations on time-lapse amplitudes. Rock physics modelling and fluid substitution studies on well logs were carried out, and acoustic impedance change in the reservoir was estimated to be in the range of $0.25 \%$ to about $8 \%$. Changes in reservoir fluid saturations were confirmed with time-lapse amplitudes within the crest area of the reservoir structure where reservoir porosity is $0.25 \%$. In this paper, we demonstrated the use of repeat Seismic to delineate swept zones and areas hit with water override in a producing onshore reservoir.
\end{abstract}

Keywords: Time-lapse, Niger Delta, Amplitudes, Basic-Sediment-Water, 4D.

\subsection{Introduction}

This research focuses on the integration of time-lapse seismic data with production data, to obtain a robust and dynamic picture of a producing reservoir. Due to increasing demand for oil and gas products, coupled with the difficulty and cost of exploring offshore, it has become necessary to look into the possibility of recovering bypassed hydrocarbons from old producing onshore fields by the application of new technologies. One of such technology is Time-lapse or 4D seismic technology which involves the acquisition, processing and interpretation of repeated seismic surveys, to monitor changes in a hydrocarbon field (Johnston et. al., 2000). If seismic is acquired over the same location with a time lapse, changes in amplitudes can therefore be evaluated (e.g. Osayande and Ugborugbo, 2009).

Time-lapse seismic technology provides an aerial view of what is happening in the sub-surface using a volume of time shifts, the monitor volume can be aligned with the base volume to produce a time aligned monitor, which can then be used to calculate an aligned difference volume. The aligned difference volume is a key input for calculating amplitude changes at the top of reservoir structure. Changes in pseudo-impedance on the top reservoir structure map which can be seen on a RMS (Root mean Square) difference map (that is, map of monitor amplitude extraction minus base amplitude extraction) (e.g. Key and Smith, 1998). Areas of amplitude increase from hydrocarbon production most times may show up as softening effect and is represented as a trough. This could be areas where; Water or oil has been replaced with gas, Water has been replaced with oil or where there have been pressure influx or pressure build up (Zou and Bentley, 2002). On the other hand, some areas show up as hardening effect, represented as a Peak on a difference map. These could be areas where; Hydrocarbons have been swept or replaced by water, or where pressure depletion has occurred. (Koster et.al., 2000). 
According to 4D conventions, areas of hardening effect are denoted with color blue, while lighter colors (yellow to orange) denotes softening effect.

The reservoir of interest here is the ' $Z$ '-reservoir of Field ' $\mathrm{K}$ ', which is a channel reservior that has been producing for several years. A base 3D survey was shot across the field in 1987, while a monitor survey was shot and processed for 4D studies in 2002 (after fifteen years of production).

\subsection{Geology of the Study Area}

The study area (figure 1) is a mature field located in the Coastal swamp Depobelt of the Niger Delta area. The Niger Delta is one of the world's largest deltaic basins, situated on the West African continental margin of the Gulf of Guinea. It lies between lat. $4^{0} \mathrm{~N}$ and $6^{0} \mathrm{~N}$ and long. $3^{0} \mathrm{E}$ and $9^{0} \mathrm{E}$, and covers a surface area of approximately $75,000 \mathrm{sq} . \mathrm{km}$. It ranges in sediment thickness from $10 \mathrm{~km}$ to $12 \mathrm{~km}$, extending more than $300 \mathrm{~km}$ from apex to mouth, and comprising a series of thick, shore parallel, southward-migrating depositional sub-basins (depobelts) with significant temporal and spatial connotations. It is sub-divided into three major lithostratigraphic sequences namely; Benin, Agbada, and Akata Formations. The Benin Formation consists of massive deposits of mainly alluvial and upper coastal plain sands with a few minor shale interbeds (Doust and Omatsola, 1990). The Agbada Formation consists of alternating sandstones and shales, the upper part having more sandstone content than the lower part. The Agbada Formation represents the delta front, distributary channels and delta plain, with the sandy part being regarded as the main hydrocarbon reservoir in the Niger Delta. The Akata Formation is the basal unit of the Tertiary Niger Delta complex, and is composed predominantly of dark grey shales with plant remains especially at its upper part. The Tertiary Niger Delta has been identified as the only petroleum system in the Nigerian Delta (Short and Staeuble, 1967).

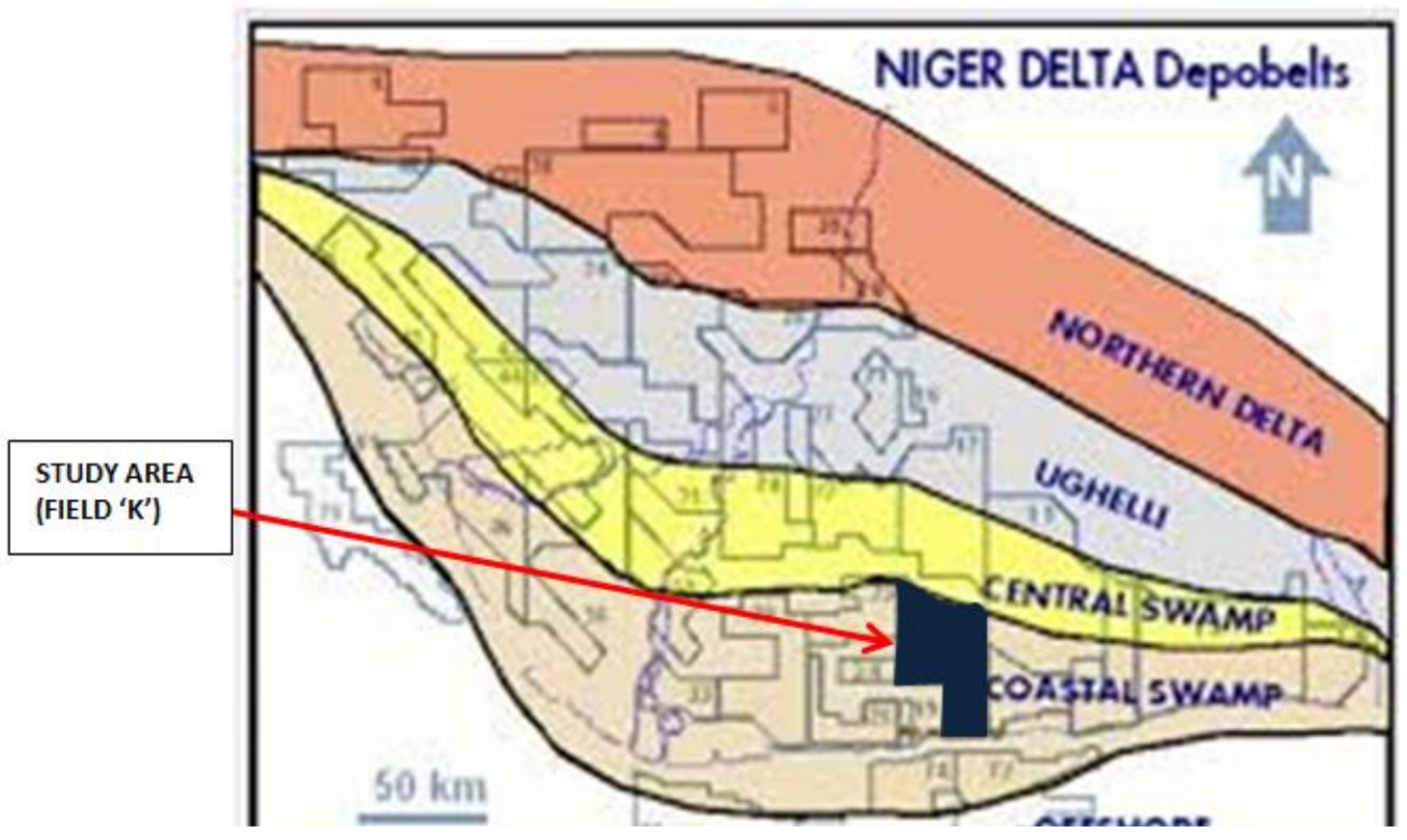

Figure.1: Outline Map of the Depobelts in the Niger Delta Basin showing location of Field 'K' (Modified after Onikoyi et. al., 2014)

\subsection{Materials and Methods}

3D base survey was acquired in 1987 and monitor survey in 2002 after 15 years of production. Monitor survey was acquired as forty eight (48) fold repeat seismic, which was re-binned to match base survey. Time aligned difference was computed using aligned monitor minus base survey. The amplitude difference was then calculated by subtracting the extracted amplitude balance of 1987 from 2002, to 
generate amplitude difference map for the horizon of interest. These difference maps illuminate timelapse amplitude changes for the 'Z'- reservoir (e.g., Kaleta, 2001).

On the difference maps, bright colours represent areas where the absolute amplitude of the seismic troughs has increased or "Brightened" between surveys (Acoustic Impedance decrease). Dark colours represent where the absolute amplitude of the seismic troughs has decreased or dimmed between surveys (acoustic impedance contrast has increased over time) (Stammeijer and Hatchell, 2014). Trace pair correlation between base and monitor traces after 4D processing work-flow was applied. Swamp area showed the least trace pair correlation as a result of challenges in repeating the source-receiver positions of the base survey.

\subsection{Results and Discussions}

The comparism of the base RMS seismic amplitude map with the monitor RMS seismic amplitude maps of 'Z'-reservoir (Figure 2) shows changes in the amplitude expression across the field either as acoustic impedance softening or hardening. As stated earlier, this variation in amplitude expression is due to changes in the acoustic impedance contrast, which could be as a result of; (i) production accompanied by either the replacement of water/oil by gas, or water by oil, (ii) pressure influx or pressure build up, (iii) replacement of hydrocarbons by water and (iv) pressure release or decrease. Scenarios (i) and (ii) result in acoustic impedance softening effect, while scenarios (iii) and (iv) result in hardening effect.

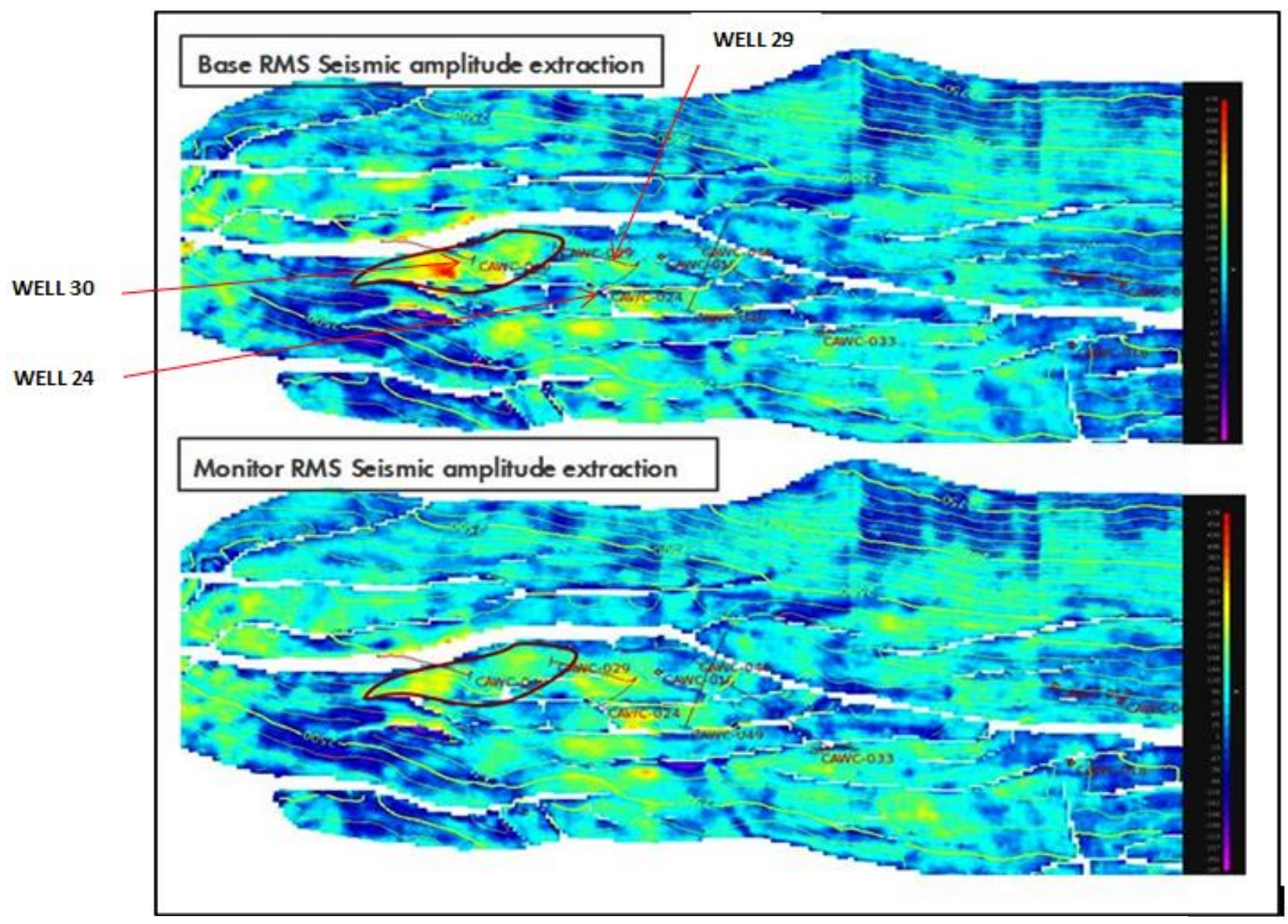

Figure 2: Base (1987) and Monitor (2002) RMS seismic amplitude extractions. Enclosed area shows dimming effect of hydrocarbon production on time lapse amplitudes around well 30 .

The Amplitude difference map for the ' $Z$ '-reservoir shows two areas of significant amplitude changes between seismic surveys (Figure 3). An area characterised by dimming/hardening effect, where amplitudes have decreased with time is marked in Figure 4a. This area represents the largest amplitude decrease on the difference map. This area is penetrated by Well 30, which produced at $29 \%$ Basic- 
sediment-water in 1988. This Basic-sediment-water increased to $70 \%$ in 2002 . The production data agrees well with the seismic data, indicating that the well has been hit by an advancing water front. A softening effect is observed around Well 29 and Well 24 (Figure 4b). Observed softening effect suggests an area of potentially un-swept opportunities in the ' $Z$ '- reservoir.

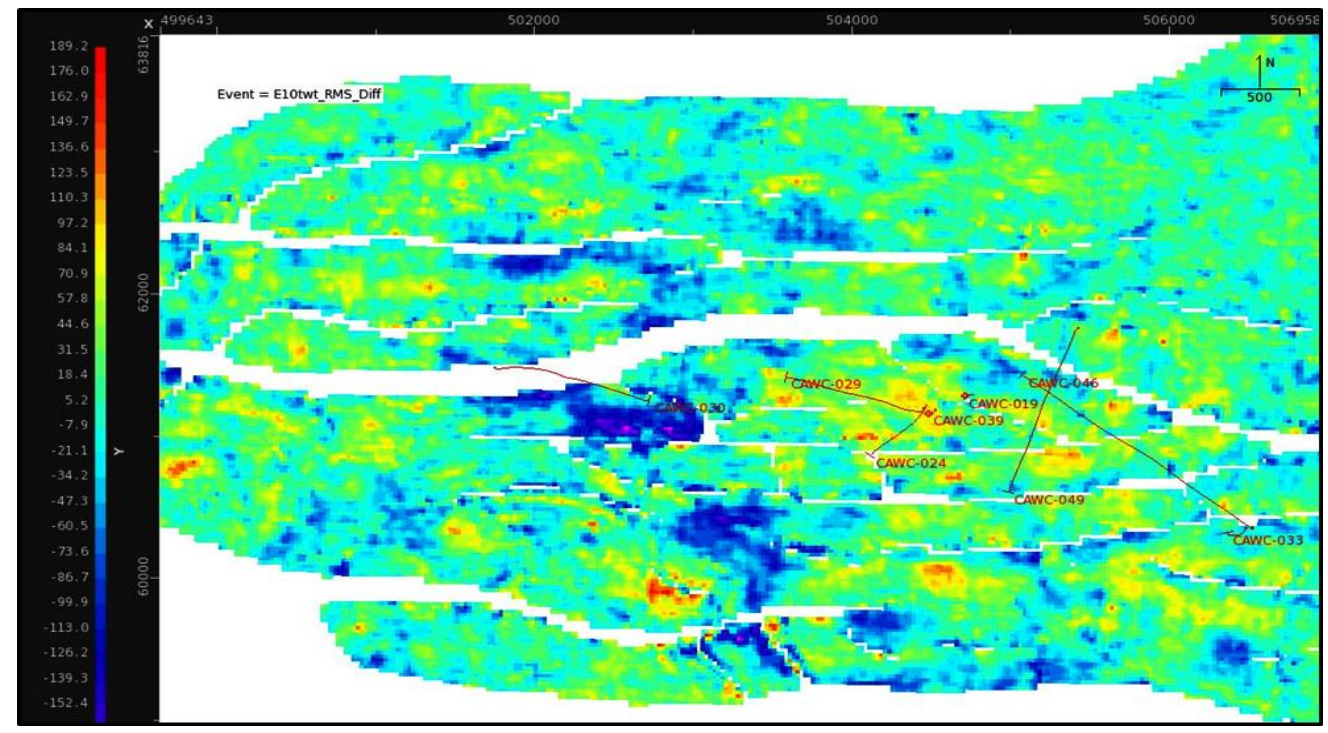

Figure 3: Amplitude difference map between base and monitor surveys for Z-reservoir

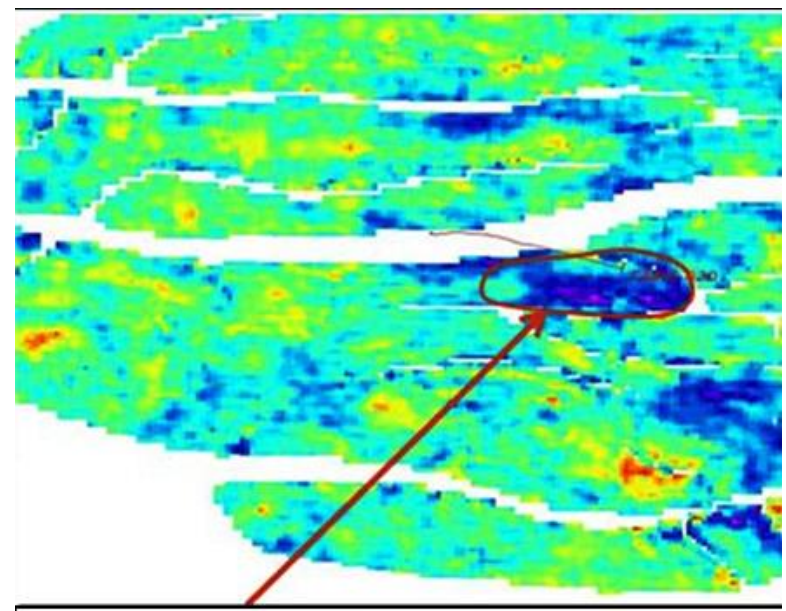

(a)

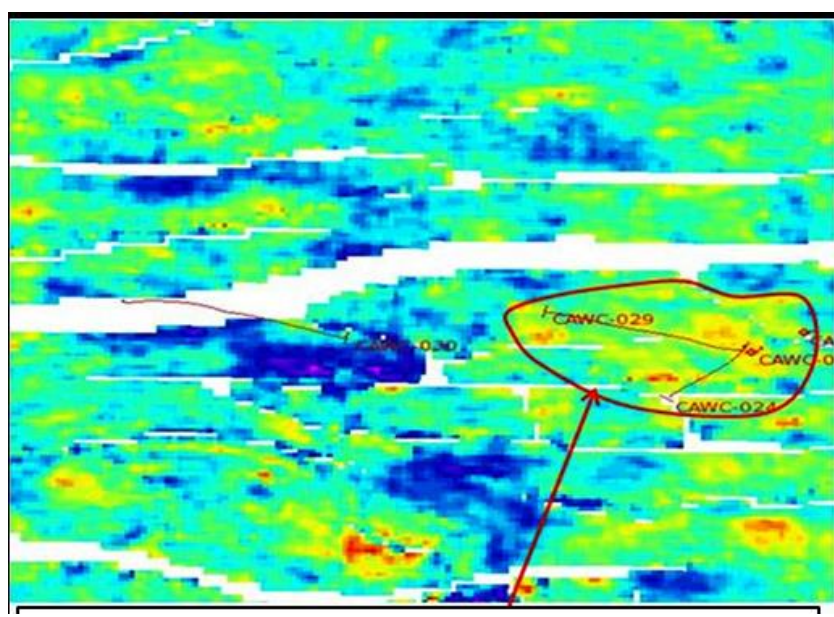

(b)

Figure 4: (a) hardening effect indicating water over-ride observed around well 30, (b) softening effect indicating un-swept $\mathrm{HC}$ opportunities observed around wells 29 and 24 


\subsection{Conclusions}

We have observed from the amplitude difference map at area around well 30, experiencing hardening as a result of production and water overriding of hydrocarbon. Time lapse amplitudes sufficiently delineated water swept zones for this mature onshore reservoir and characterized production effects for producing wells in this field. Also, areas around well 24 and well 29 experiences softening effect characteristics of unswept hydrocarbon zone (This zone represents areas of untapped hydrocarbon). The possibility of communication between structures found around well 30 and well 24 and 29 is possible hence, the advancing waterfront must have driven hydrocarbon from areas around well 30 during production to areas around well 24 and 29 , in the process concentrating water around well 30 . Hence, the hardening effect observed around well 30 and the corresponding softening effect around well 24 and 29.

\section{References}

Onikoyi, A.S., Nwabueze, V.O., Okoro, F.O., and Ajienka, J.A., (2014). 'Review of Sand Production from Oil Well Completions Across Depositional Environments in the Niger Delta', SPE Conference paper 2014, Paper ID: SPE-172484-MS, pp. 12

Doust. H, and Omatsola, E.M., (1990). 'Niger Delta' In: Divergent/Passive Margin Basins, D. Edwards and P.A. Santagrossi (eds.), AAPG Memoir 45, p. 201-238.

Osayande, F., and Ugborugbo, O., (2009). 'Time-Lapse Feasibility Studies of Two Fields in the Niger Delta', SPE Conference paper 2009, Paper ID: SPE-128362-MS, pp. 5

Stammeijer J.G.F. and Hatchell, P.J., (2014). 'Standards in 4D Feasibility and interpretation', The Leading Edge, Vol. 33, p. 134-140

Johnston, D.H., Eastwood, J.E., Shyeh, J.J., Vauthrin, R., Khan, M., \& Stanley, L.R., (2000). 'Using legacy seismic data in an integrated time-lapse study: Lena field, Gulf of Mexico', The Leading Edge, Vol. 19, p. 294-302.

Kaleta, N., (2001). 'Time-Lapse (4D) Seismic Investigation of the I3 and TA2 Sands, Kilauea Field, Green Canyon Block 6, Gulf of Mexico', Unpublished Master's thesis submitted to the Pennsylvania State University, pp. 90.

Key, S.C., and Smith, B.A. (1998). 'Seismic reservoir monitoring: application of leading-edge technologies in reservoir management', Proceedings-Offshore Technology Conference, Vol. 30, p. 153161

Koster, K., Gabriels, P., Hartung, M., Verbeek, J., Deinum, G. and Staples, R., (2000). 'Time-lapse seismic surveys in the North Sea and their business impact'. The Leading Edge, Vol. 19, p. 286-293.

Short K.C., and Staeuble, A.J., (1967). 'Outline of Geology of Niger Delta', AAPG Bulletin, Vol. 51, no. 5, p. 761-799.

Zou, Y. and Bentley, L.R., (2002). 'Time-lapse Seismic Analysis Using Well Logs', CSEG Geophysics, pp. 4. 